\title{
Theoretical basics and experimental methods of consideration of the concrete mixtures' movement resistance in the concrete-delivery pipelines
}

\author{
Sergey Novikov*, Boris Zhadanovsky and Sergey Sinenko \\ Moscow State University of Civil Engineering, Department of Construction Technology and \\ Organization, Yaroslavskoe chaussee 26, Moscow, Russian Federation
}

\begin{abstract}
The directions associated with development and improvement in the field of works' production using the concrete and reinforced concrete are related mainly with the improvement of the quality and durability of concrete and products based on it, the rational use of material and energy resources. The research points to the necessity of determination of the exploitative performance with considering the certain factors of influence on the construction technological processes wherein the factor related with abrasiveness and aggregates size has not been fully studied. The methodology for laboratory studies of the slip velocity of a concrete mixture in the concrete-delivery pipelines is proposed: theoretical methods for estimating the resistance to movement of concrete mixtures are determined. The method for determining the specific resistance to the movement of concrete mixtures using an installation that takes into account resistance to movement of abrasive mass has been developed. Thus, the developed methods of accounting the resistance to the movement of concrete mixtures in concrete-delivery pipelines make it possible to substantially save the cost of transporting the concrete mixture with the best exploitative performance.
\end{abstract}

\section{Introduction}

The problem of saving resources in the construction industry has recently been particularly acute and has become one of the most relevant. In the light of slowing the growth of the world economy, the Governments of the developed and developing countries have consistently taken decisions in the field of strategic planning, improving management, increasing the efficiency of spending and consolidating budgetary funds and implementing public procurement, improving the conditions for entrepreneurial activity [1,2].

Quite reasonably and expectedly there was a need for the development and improvement of directions in the field of construction and assembly works (CAW) using concrete and reinforced concrete, as the most common building materials. These directions are mainly related to the rational use of material and energy resources and their savings

\footnotetext{
*Corresponding author: 6622040@mail.ru
} 
along with directions related with the improvement of the quality and durability of concrete and products based on it.

Currently building organizations widely use various methods of construction of buildings and structures, in the latter time of the monolithic construction is one of the most commonly used production methods of construction, in recent years, the solid-cast construction is one of the most frequently used methods of executing the CAW, and therefore the share of concrete pumps, as one of the most common technologies of solidcast concreting of structures during the erection of buildings and structures, increases year by year [3].

In this way the research in the field of increasing the productivity of concreting technology using concrete pumps acquires the relevance.

\section{The accounting for tractive resistance of concrete mixtures in concrete conveying pipes (CCP)}

When pumping concrete mixtures in concrete conveying pipes of various types of concrete pumps, specific factors of influence on the technological process in the conditions of a certain construction site should be considered in order to determine the productivity [4].

\subsection{The factors of influence on the CCP's productivity}

These factors of influence, respectively, depend on:

- the rheological properties of the mixture (water and cement ratio, plasticizers, etc.);

- the abrasive properties of coarse and fine aggregate (mold);

- the volumes of fraction of fine aggregate in the concrete mixture;

- the fineness of aggregate and its type;

- the flow rate and fineness of grind;

- the grade of cement;

- the diameter of the concrete conveying pipe;

- the height and range of the horizontal delivery capacity;

- the distance of the abrasive friction of the coarse aggregate;

- the number and type of sections of increasing the mixture tractive resistance (cones, elbows, etc.);

- the material of the concrete conveying pipe (steel, rubber-fabric hose, etc.).

Researchers from different countries have sufficiently studied the influence of the above factors affecting the technological process for pumping concrete mixtures in concrete conveying pipes of various concrete pumps types, while the factor associated with abrasiveness and the fineness of aggregates has not been fully studied to date $[5,6]$.

Besides, the manufacturers in their passports for the supplied equipment usually indicate their technical performance while the construction organizations must operate with their operational performance for rational and effective use in specific conditions of use of concrete pumps.

When designing the execution of construction and assembly works in the required conditions of the construction site, the type of a concrete pump is selected according to its main characteristic specified in the equipment passport "Technical Performance", which depends on the pressure of the manometric head piston on the concrete mixture, which in turn is determined considering the manometric head loss in the pipeline at transporting the mixture and changing the performance of the concrete pump under load [7]. 


\subsection{The hydraulic resistances of concrete mixtures in pipelines}

As it is known, losses in pipeline $(P)$ depend on the specific tractive resistances of the concrete mixtures $(\Delta P)$, the total length of the concrete conveying pipe $(l)$ and the size of its vertical section $(h)$, as well as from local manometric head losses in the adapter sleeve and elbows $\left(P_{k}\right)$. These losses in pipelines are determined by the expression 1 .

$$
P=\Delta P l+P_{k}+\gamma h \cdot 10^{-5}
$$

Where:

- $\Delta P$ - the specific tractive resistance of the concrete mixture at $1 \mathrm{~m}$ horizontal part of the concrete conveying pipe, $\mathrm{MPa} / \mathrm{m}$;

- $l$ - total length of the concrete conveying pipe, $\mathrm{m}$;

- $P_{k}$ - local manometric head losses in the adapter sleeve and elbows, MPa;

- $\gamma h \cdot 10^{-5}$ - the manometric head losses equal to the hydrostatic pressure of a concrete mixture of the volume mass $\gamma\left(\mathrm{kg} / \mathrm{m}^{3}\right)$ in the vertical section of a concrete conveying pipe of height $h(\mathrm{~m}), \mathrm{MPa}[8]$.

The specific tractive resistance of concrete mixtures in the pipeline depends on the nature and speed of their movement, the composition and mobility of the mixture, the size and type of aggregate, the proportion of sand in the aggregates, the material of the concrete conveying pipe and its internal diameter. The nature of the concrete mixtures' movement in the pipeline in structural mode presented at Figure 1.

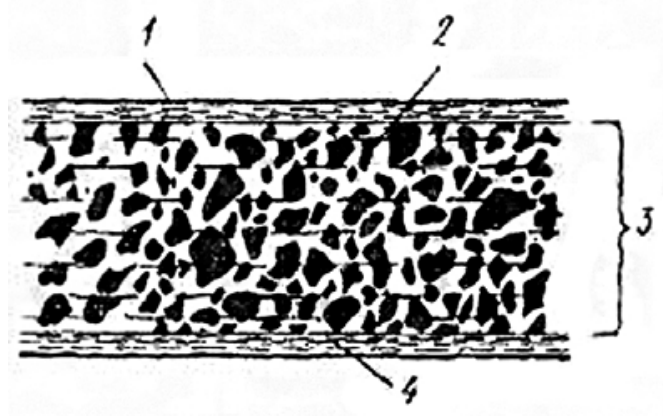

Fig. 1. The nature of the concrete mixtures' movement in the pipeline in structural mode: 1 . Pipe's side; 2. Cement-sand mortar; 3. Main mixture's flow; 4. Side-mounted anointing layer.

The specific tractive resistance of concrete mixtures $\Delta P$ with mobility up to $10 \mathrm{~cm}$ is recommended to be determined by the expression 2 .

$$
\Delta P=\left(a \sqrt{ } V+\Delta P_{0}\right) F_{\mathrm{d}} F_{\mathrm{M}} F_{\mathrm{N}} F_{\mathrm{A}}
$$

Where:

$-\Delta P_{0}$ - the shearing resistance on one horizontal section of the pipeline when $V_{0}=0, \mathrm{~m} / \mathrm{s}$;

- $V$ - the speed of transportation of the mixture, $\mathrm{m} / \mathrm{s}$;

$-a$ - the factor depending on the mobility and composition of the mixture, $\mathrm{MPa} \cdot(\mathrm{s} / \mathrm{m})^{1 / 2}$;

$-F_{\mathrm{d}}=\mathrm{D}_{100} / \mathrm{D}_{\mathrm{X}}$ - the factor of change of the tractive resistance of the mixture depending on the internal diameter of the pipeline;

- $\mathrm{D}_{100}, \mathrm{D}_{\mathrm{X}}$ - the internal pipeline diameter, respectively, equal to $100 \mathrm{~mm}$; and the diameter used in practice, $\mathrm{mm}$;

- $F_{\mathrm{M}}$ - the factor of change of the tractive resistance of the mixture depending on the material of the pipeline; $F_{\mathrm{M}}=1,0$ - for steel pipelines, $F_{\mathrm{M}}=1,5-$ for rubber hoses. 
- $F_{\mathrm{N}}$ - the factor of the transition from uniform to non-uniform movement of the mixture; $F_{\mathrm{N}}=1,0$ - for uniform movement of the mixture; and for the non-uniform - pulsation one $F_{\mathrm{N}}=1,5$;

- $F_{\mathrm{A}}$ - the factor considering the influence of the coarse aggregate on the value of the resistances. For crushed stone $F_{\mathrm{A}}=1$, for gravel $F_{\mathrm{A}}=0,8[9,10]$.

At the same time, the last factor does not specify which resistances consider the influence of the type of the coarse aggregate (the internal resistance of the concrete mixture or the resistance "aggregate-wall of the concrete conveying pipe"), and in this case the fineness of the aggregate, and hence the property of aggregate abrasiveness, i.e. the ability of the aggregate to wear out the surfaces of the parts of the concrete conveying pipes of the concrete pump equipment in contact with it during its operation.

\subsection{The experimental research of the concrete mixtures' movement resistance in the concrete-delivery pipelines}

It was suggested to clarify this factor empirically by carrying out the laboratory researches of the abrasiveness factors and the shape of the coarse aggregate of the concrete mixture. It is necessary to prove whether the aggregate fineness affects the speed of transportation of the concrete mixture. A special experimental installation represented at Figure 2 has been designed to simulate the passage of a concrete mixture along a concrete conveying pipe.

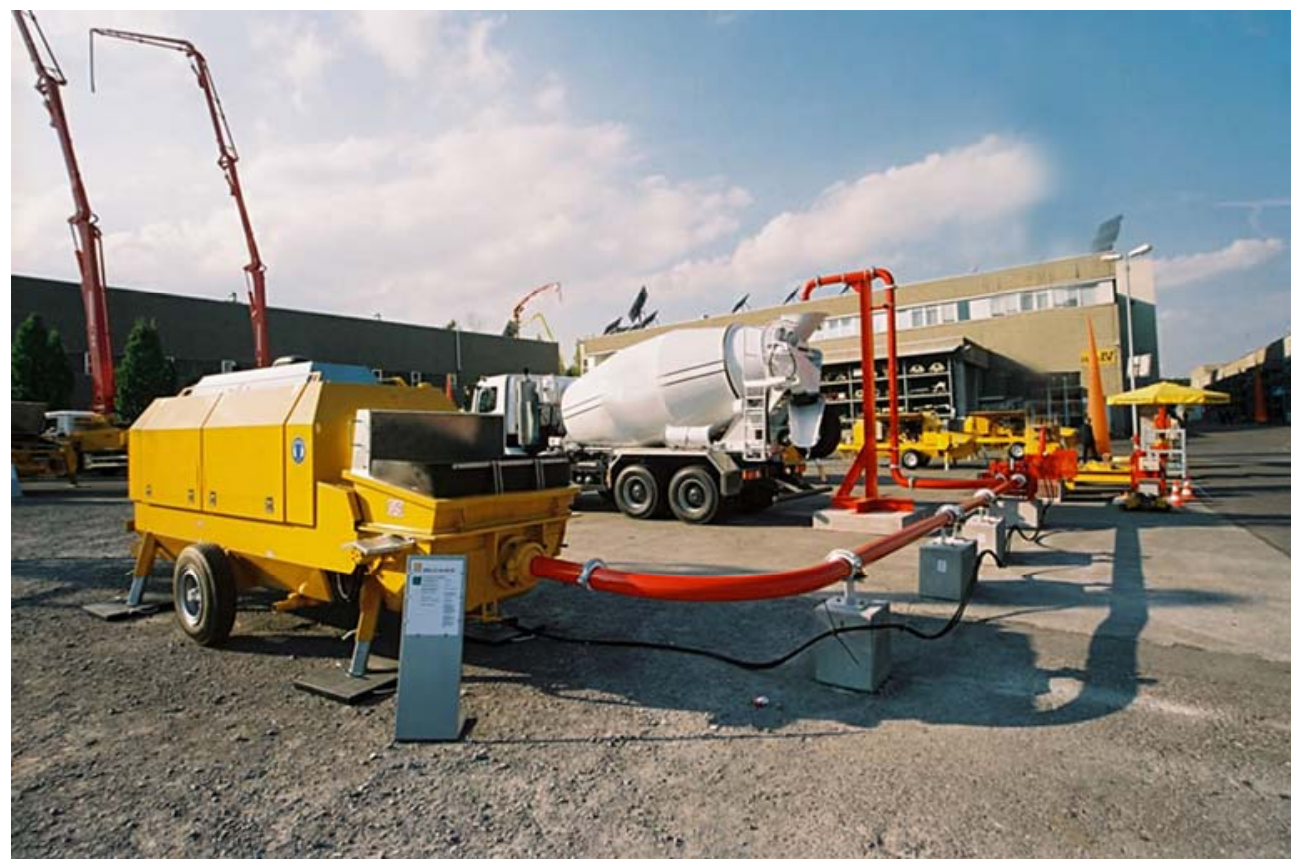

Fig. 2. Experimental stand for laboratory determination of the concrete mixture's sliding speed.

The experiment was carried out with a horizontal pipe of $12 \mathrm{~m}$ (3 straight and 1 rounded pipe sections) and $160 \mathrm{~mm}$ caliber, a concrete pump of $15 \mathrm{~m}^{3} / \mathrm{h}$ performance. The stand is presented in plan at the drawing, Figure 3. 


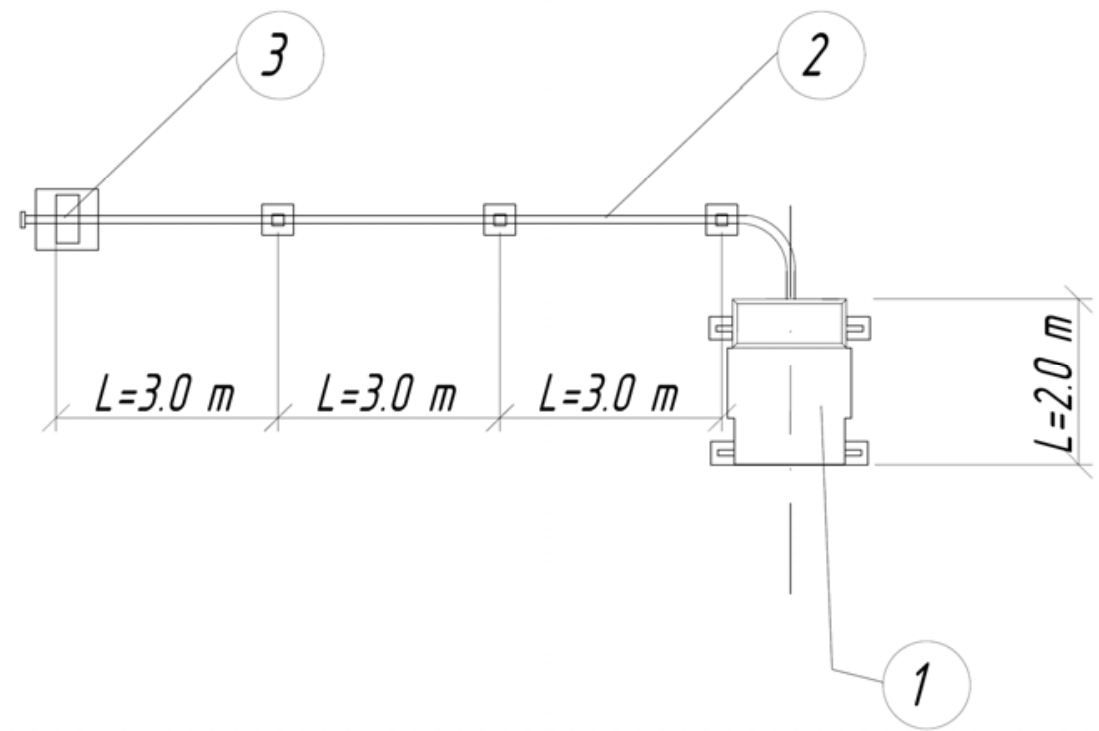

Fig. 3. The drawing of the experimental stand: 1. Concrete pump; 2. Concrete-delivery pipeline; 3. Pressure sensor.

Due to the workability of the concrete pump, the phenomenon, fresh concrete mixture with various aggregates being pulled from the pumping reservoir and pushed into the pipes, may be fixed at the end of the pipe by a pressure sensor. The fact of the complete pipe's depletion designates the end of the part of experiment. The duration of passage of the concrete mixture was recorded by a stopwatch, also the pressure in the end of the conveying pipe was measured by pressure sensor.

The methods of the laboratory researches of the sliding speed of a concrete mixture with various aggregates may be divided into 3 blocks: 10-20 mm, 20-40mm, $40-70$ fractions. The results of laboratory researches presented in Table 1, pointed to a different speed of movement of the concrete mixture along the concrete conveying pipe, which confirmed the hypothesis put forward.

Table 1. The movement speed of the concrete mixture with various aggregates and the value of fraction gradation coefficient

\begin{tabular}{|c|c|c|}
\hline Fraction, $\mathbf{m m}$ & Speed, $\mathbf{m} / \mathbf{s}$ & $\begin{array}{c}\text { Fraction coefficient, } \\
\boldsymbol{F}_{\boldsymbol{A}}{ }^{*}\end{array}$ \\
\hline $10-20$ & 0,71 & 0,74 \\
\hline $20-40$ & 0,63 & 0,88 \\
\hline $40-70$ & 0,56 & 1 \\
\hline
\end{tabular}

Thus, discovering that different groups of the mix proportion has different pressure at the same volume and pump performance it is possible to claim that the influence of mixture's fraction gradation should be included in the factor $F_{\mathrm{A}}$ considering the influence of the coarse aggregate on the value of the resistances.

Let introduce the Fraction coefficient which would be equal $F_{\mathrm{A}}{ }^{*}=1$ for fractions of 40 $70 \mathrm{~mm}$. Then the value of fraction gradation coefficient may be accepted intercalary with it appropriate transition speed according to Table 1 .

Thereby the equation 2 may be modified in formulae 3 


$$
\Delta P=\left(a \sqrt{ } V+\Delta P_{0}\right) F_{\mathrm{d}} F_{\mathrm{M}} F_{\mathrm{N}} F_{\mathrm{A}}^{*}
$$

Where

$-\Delta P_{0}, V, a, F_{\mathrm{d}}, F_{\mathrm{M}}, F_{\mathrm{N}}$ are the same (see eq. 2 );

- $F_{\mathrm{A}}$ - the factor considering the influence of the coarse aggregate on the value of the resistances. For crushed stone with:

- 10-20mm fractions $-F_{\mathrm{A}}{ }^{*}=0,74$;

- 20-40mm fractions $-F_{\mathrm{A}}{ }^{*}=0,88$;

- 40-70mm fractions $-F_{\mathrm{A}}{ }^{*}=1$;

\section{Conclusion}

Thus, it is proved that the fineness of the aggregate affects the tractive resistance of concrete mixtures in concrete conveying pipes and so the required additional accountings in the specific tractive resistance formula are made. The factor considering the influence of the coarse aggregate on the value of the resistances was studied at large by dint of designing an experimental stand for laboratory determination of the concrete mixture's sliding speed during which empirically identified direct influence of mixture's fraction gradation on specific tractive resistance of concrete mixtures. These achievements handed to understand the factor associated with abrasiveness in concrete-delivery pipes, to bring closer the theoretical basics of consideration of the concrete mixtures' movement resistance through exploitative performance, to establish the basis for the next steps of researching in this domain that might be related with other factors that affects hydraulic resistances of concrete mixtures in pipelines.

\section{References}

1. A.V. Kiyanets, Proc. Eng. 150, 2125 (2016)

2. S.O. Novikov, Matec Web of Conf. 86, 04032 (2016)

3. V.S. Semenov, E.V. Tkach, S.A. Tkach, T.A. Rozovskaya, Proc. Eng. 111, 763 (2015)

4. S.O. Novikov, A.A. Sapukhin, Proc. of MSUCE 7, 96 (2013)

5. N.S. Blokhina, AMM 2687, 405-408, (2013)

6. V.S. Semenov, E.V. Tkach, S.A. Tkach, T.A. Rozovskaya, Proc. Eng. 111, 763 (2015)

7. B.V. Zhadanovsky, S.A. Sinenko, Science Review 9-2, 435 (2014)

8. B.V. Zhadanovsky, S.A. Sinenko, AMR 280. 838-841 (2013)

9. C.-T. Mai, E. Kadri, T.-T. Ngo, A. Kaci, M. Riche, AMSEV 2014, 503850 (2014)

10. A.A. Lapidus, Proc. of MSUCE 7, 96 (2013) 